\title{
A Sociocultural Exploration of Sex-Bias in NSERC-funded Human Cardiovascular Research at Ontario Universities
}

Ria Wilson, Kinesiology and Health Studies

14rcew@queensu.ca

Faculty Supervisors: Dr. Kyra Pyke \& Dr. Mary L. Adams 


\section{Queen's}

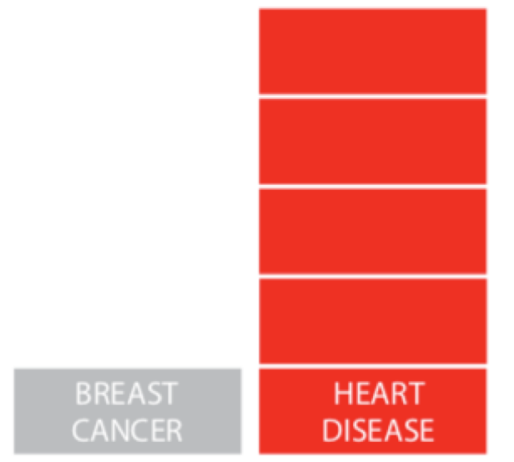

Women are 5X more likely to die from heart disease than breast cancer.
Every.

20 minutes

a woman in

Canada dies from

heart disease.

(Heart \& Stroke Foundation, 2018) 
Despite these staggering statistics...

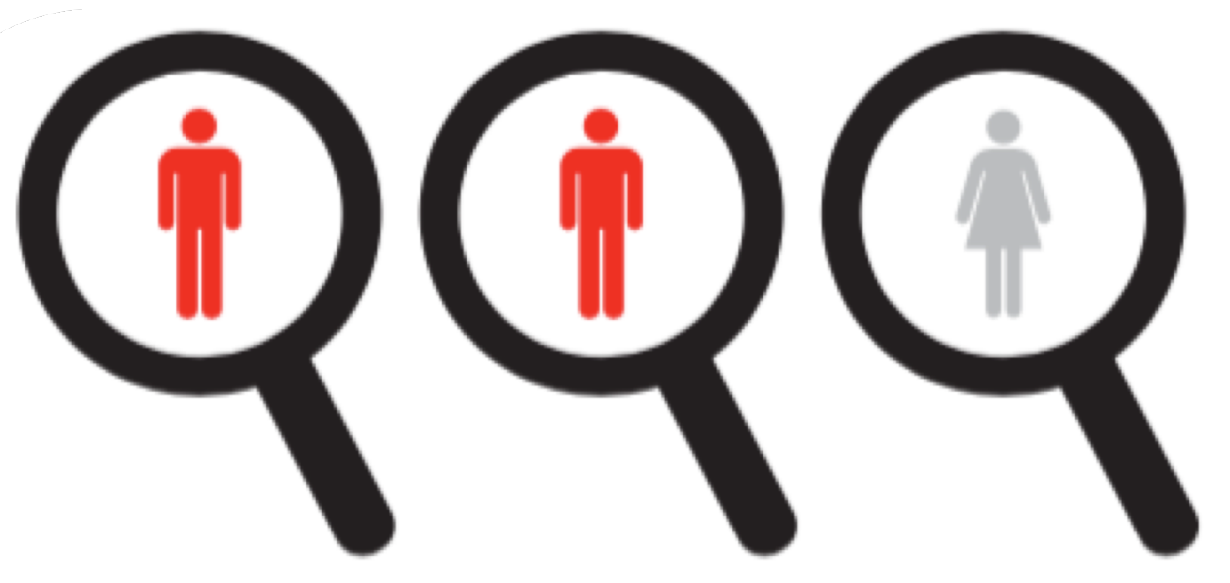

2/3 of heart disease clinical researchfocuses onmen. 


\section{Outline}

\section{Queen's}

- Background

- What do we know about sex-bias against the inclusion of women in research?

- What is being done to address this sex bias?

- Part I

- Research question

- Methods

- Results

- Part II

- Research question

- Methods

- Take home message 


\section{Background}

\section{Where did this sex-bias come from?}

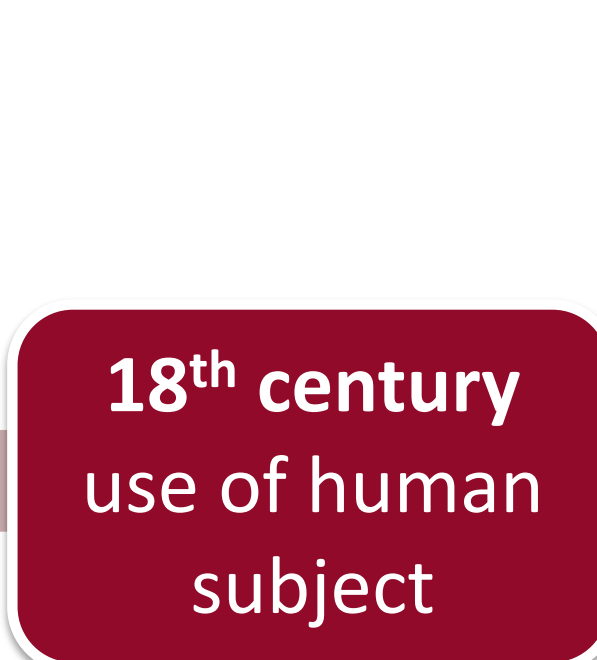

\section{Late $19^{\text {th }}$ century methodological standardization}

The 'normal' male body

(Epstein, 2007; Kaufert, 1999; Institute of Medicine (US) Committee on Ethical and Legal Issues Relating to the Inclusion of Women in Clinical Studies, 1994)

Male norm: male body is viewed as the 'standard' human body. Female body is understood only in how it deviates from this 'standard'. 


\section{Background}

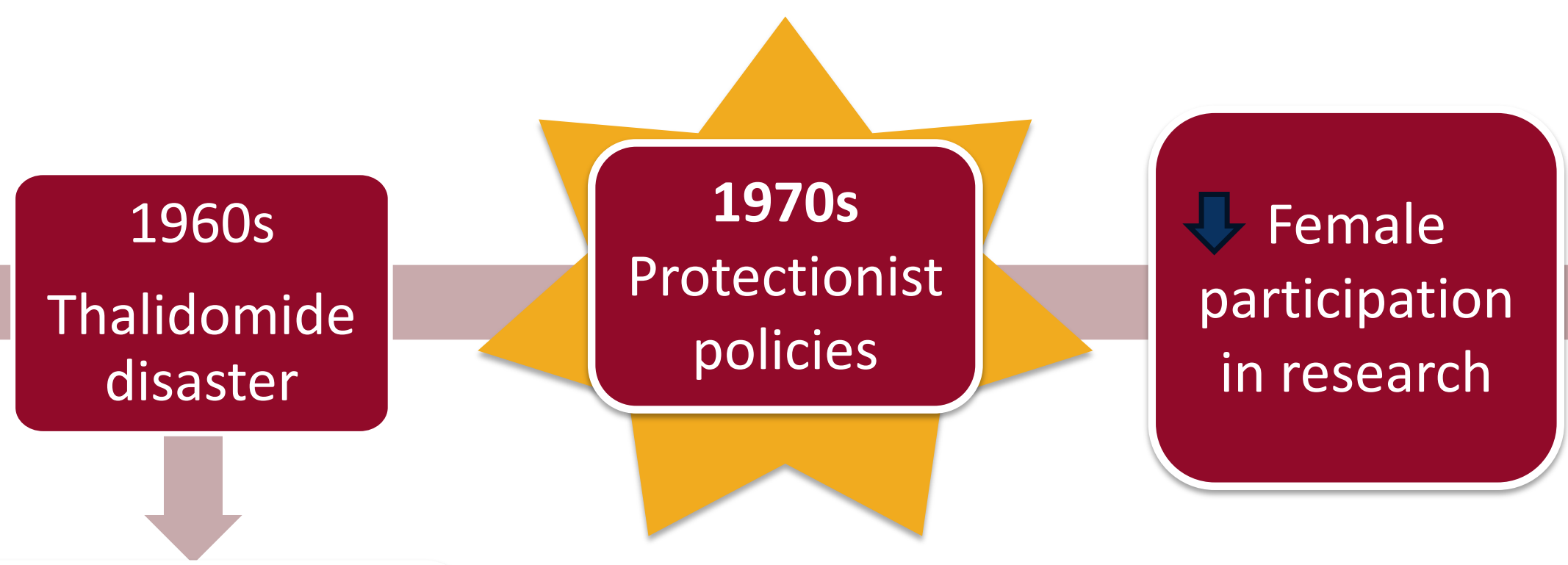

PROTECTIONISM

(Epstein, 2007) 


\section{Background}

\section{0s/1990s}

Calls for inclusion

of women in

$$
\text { research }
$$

(Epstein, 2007; Lippman, 2006; Government of Canada, 2016)
Introduction of inclusion guidelines, policies

TCPS2 2014

TRI-COUNCIL POLICY STATEMENT

Ethical Conduct for Research Involving Humans

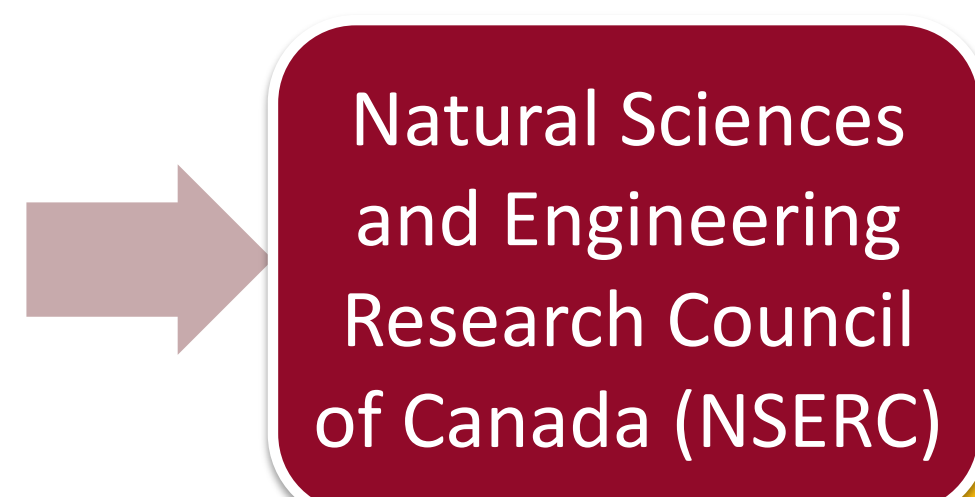

Canadian Institutes of Health Resaarch 
Part I-Research Question

Queen's

Despite inclusion guidelines, does the bias persist?

TCPS2 2014

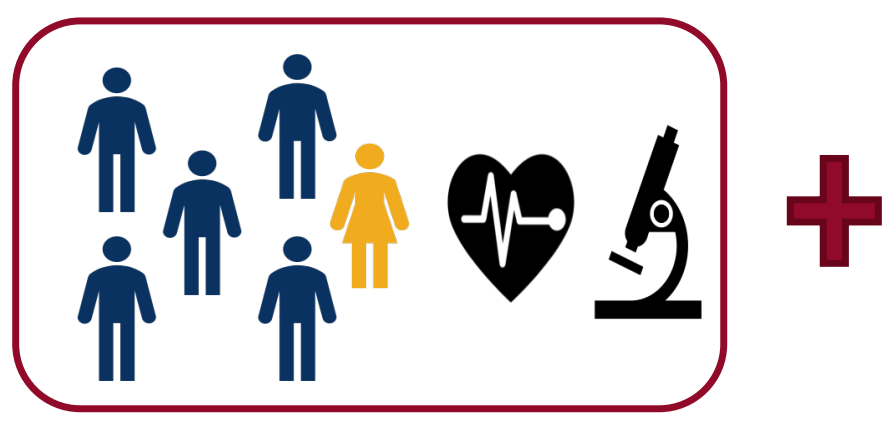

TRI-COUNCIL POLICY STATEMENT

Ethical Conduct for Research Involving Humans

2014

Canadian Institutes of Health Research

政
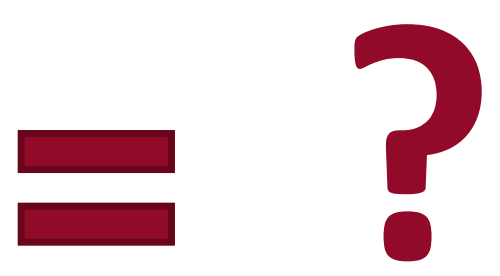


\section{Part I - Statement of significance}

Queen's

Is human cardiovascular research at Ontario universities following TCPS2 inclusion guidelines? 


\section{Part I - Methods}

\section{4}

NSERC Discovery Grant-funded cardiovascular research publications from Ontario universities between 2010-2018.

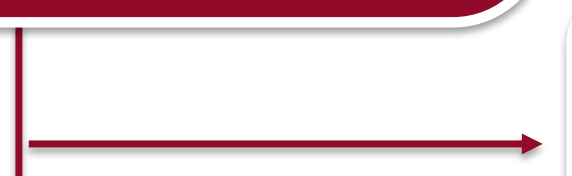

\section{4}

\section{Publications excluded}

\section{3}

Duplicates removed

Publications to undergo appraisal 
Part I - Results
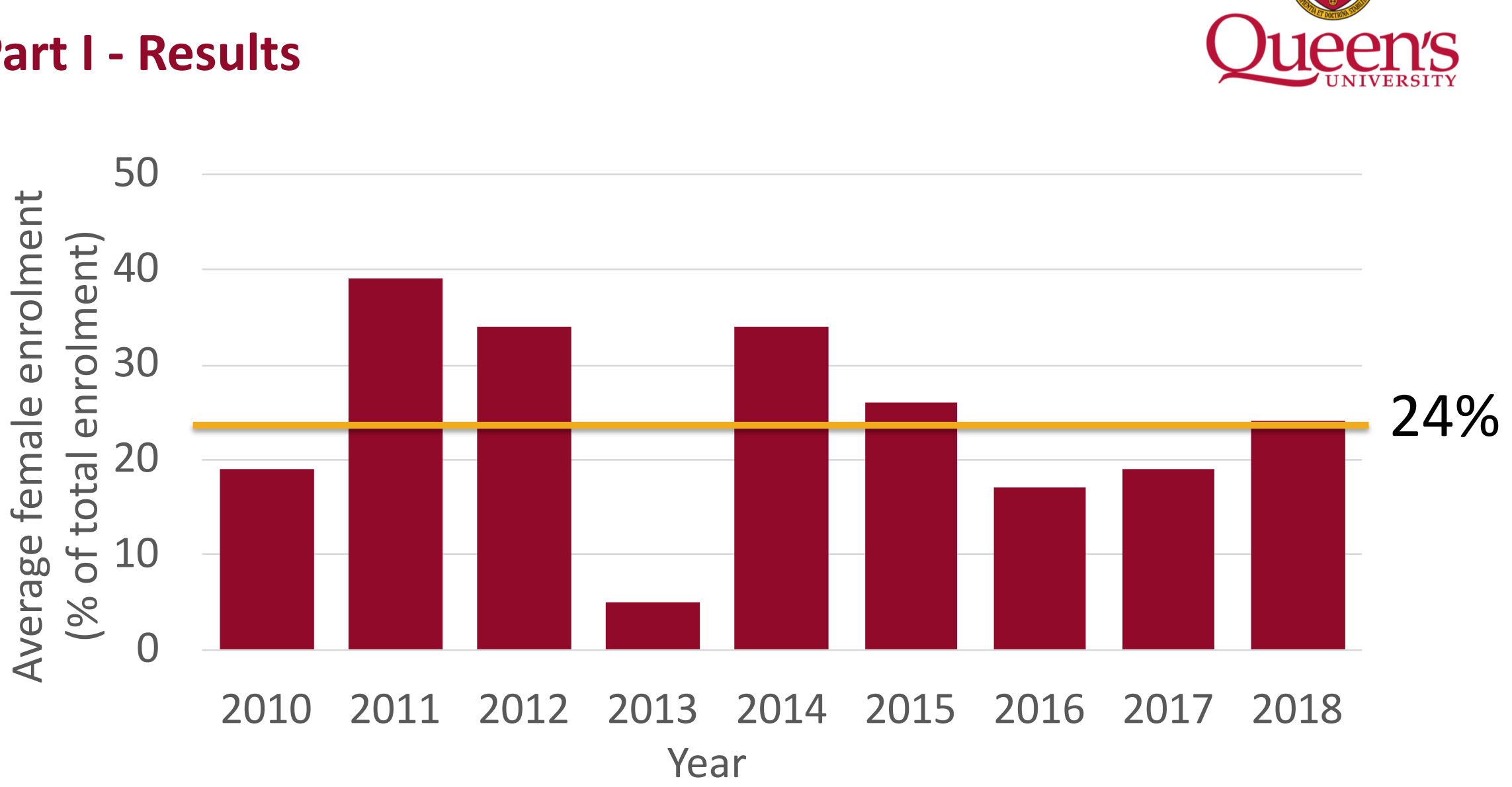

Fig. 2. Average female enrolment in NSERC Discovery Grant funded human cardiovascular research at Ontario universities from 2010-2018. 


\section{Part I - Results}

Queen's

Female inclusion in NSERC Discovery Grant-funded human cardiovascular research at Ontario universities from 2010-2018

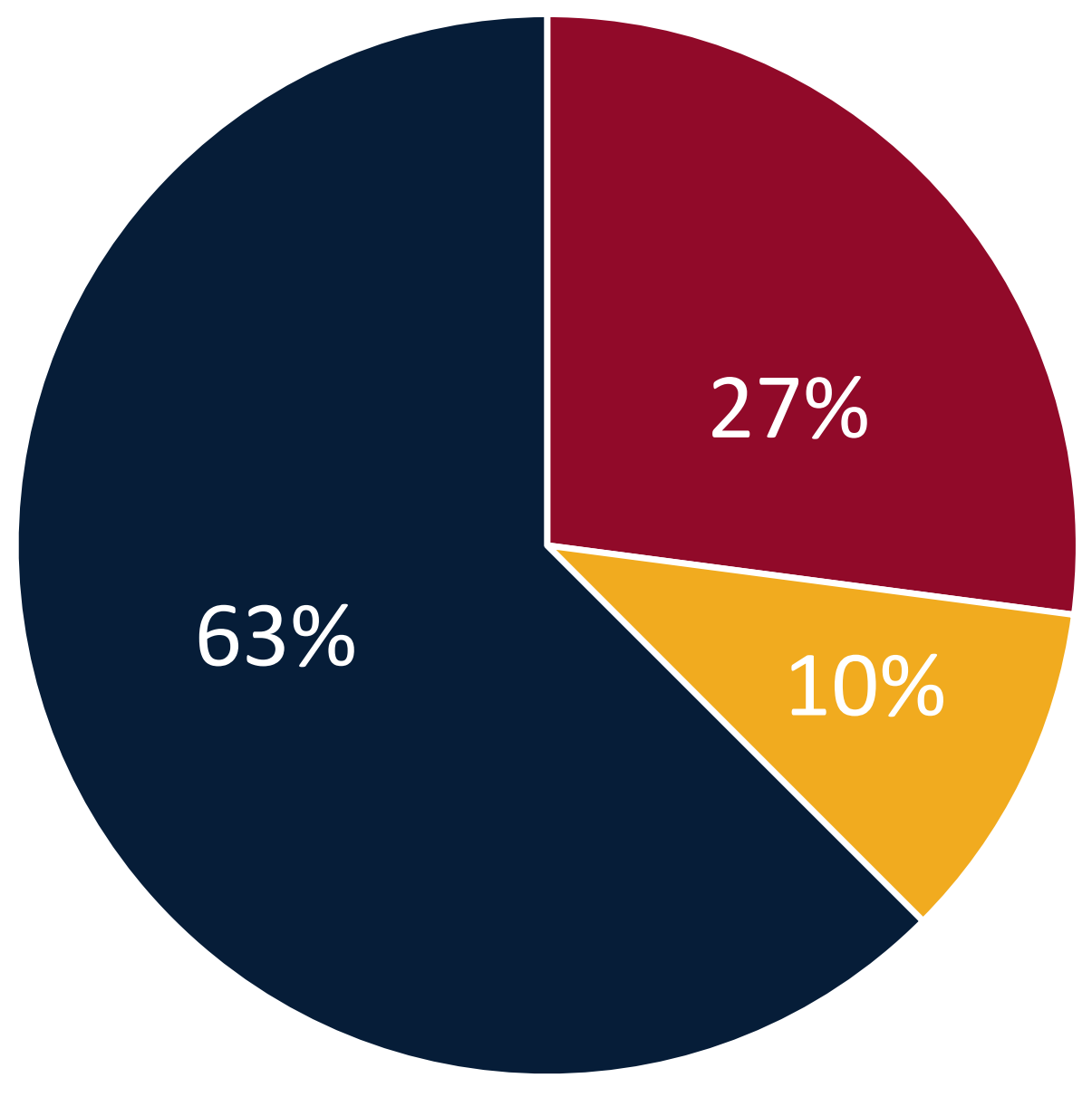

- Equal male and female inclusion

- Female overrepresentation

- Female underrepresentation or exclusion 


\section{Part II - Sociology of science}

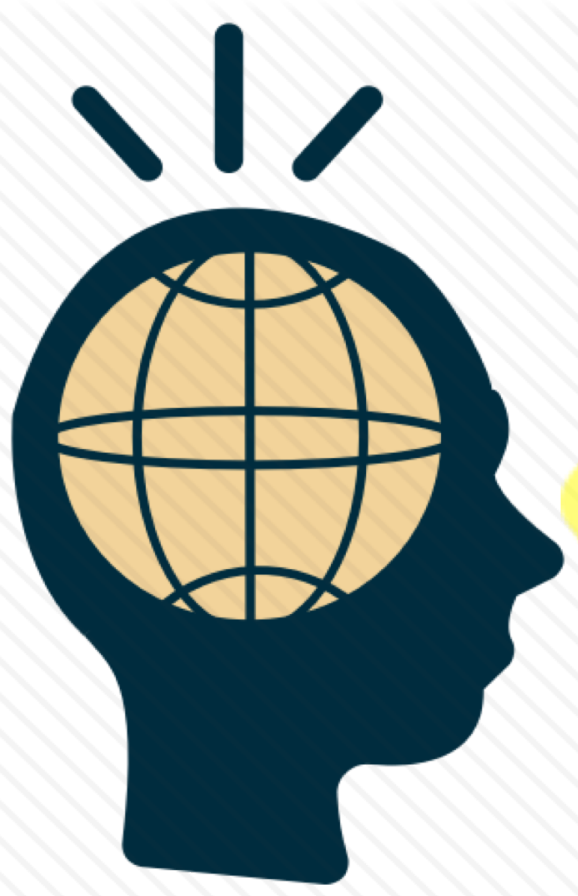

\section{What explains this sex-bias?}

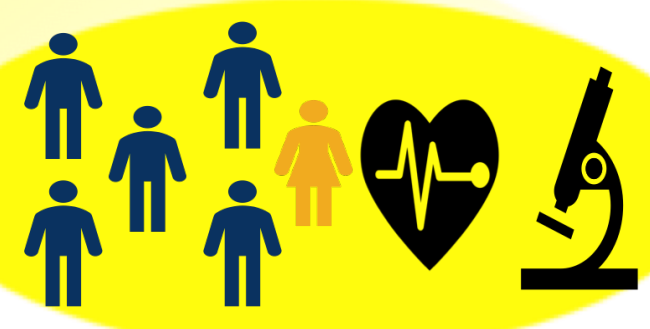




\section{Part II - Hypothesis}

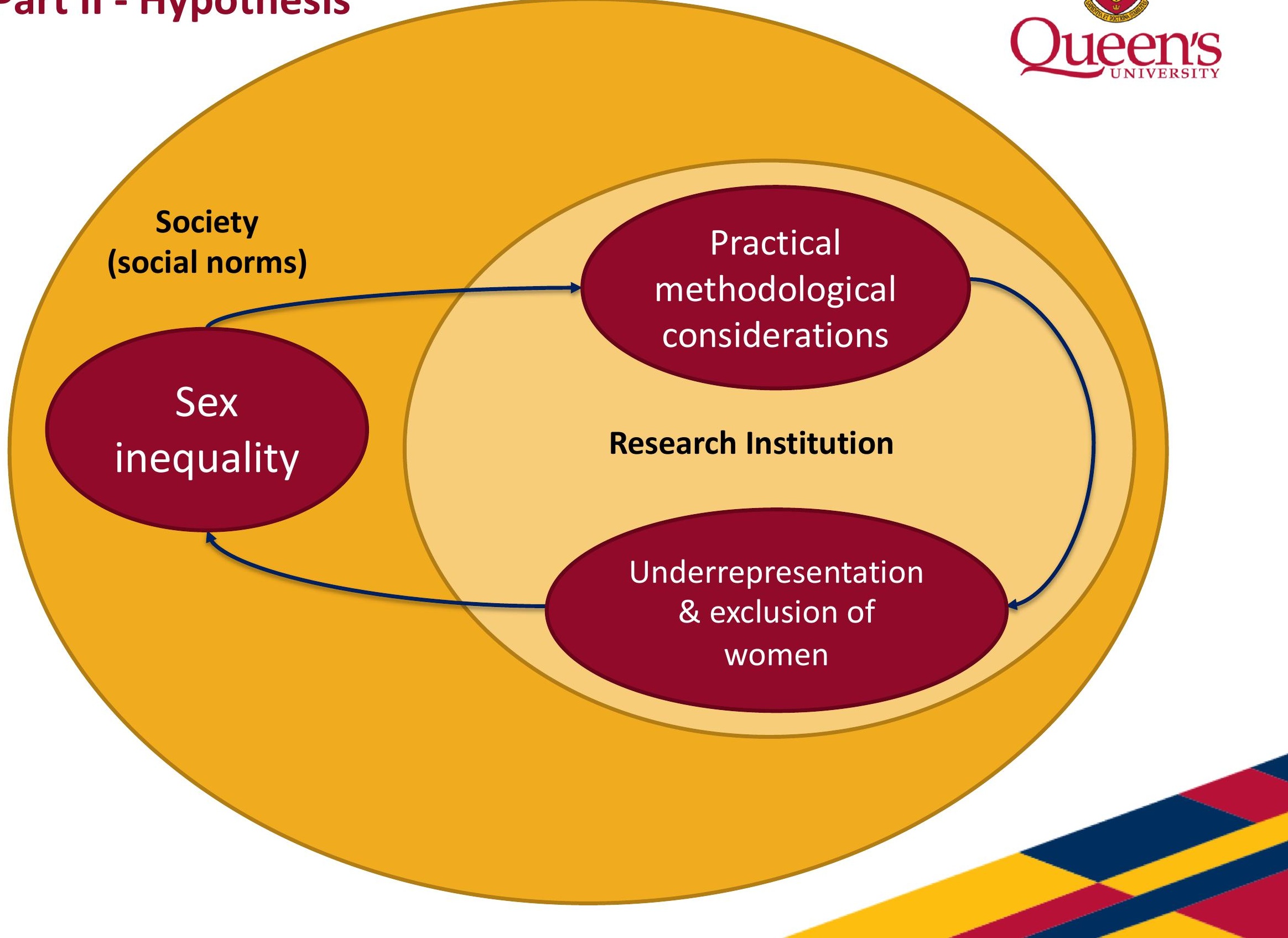




\section{Practical methodological considerations}

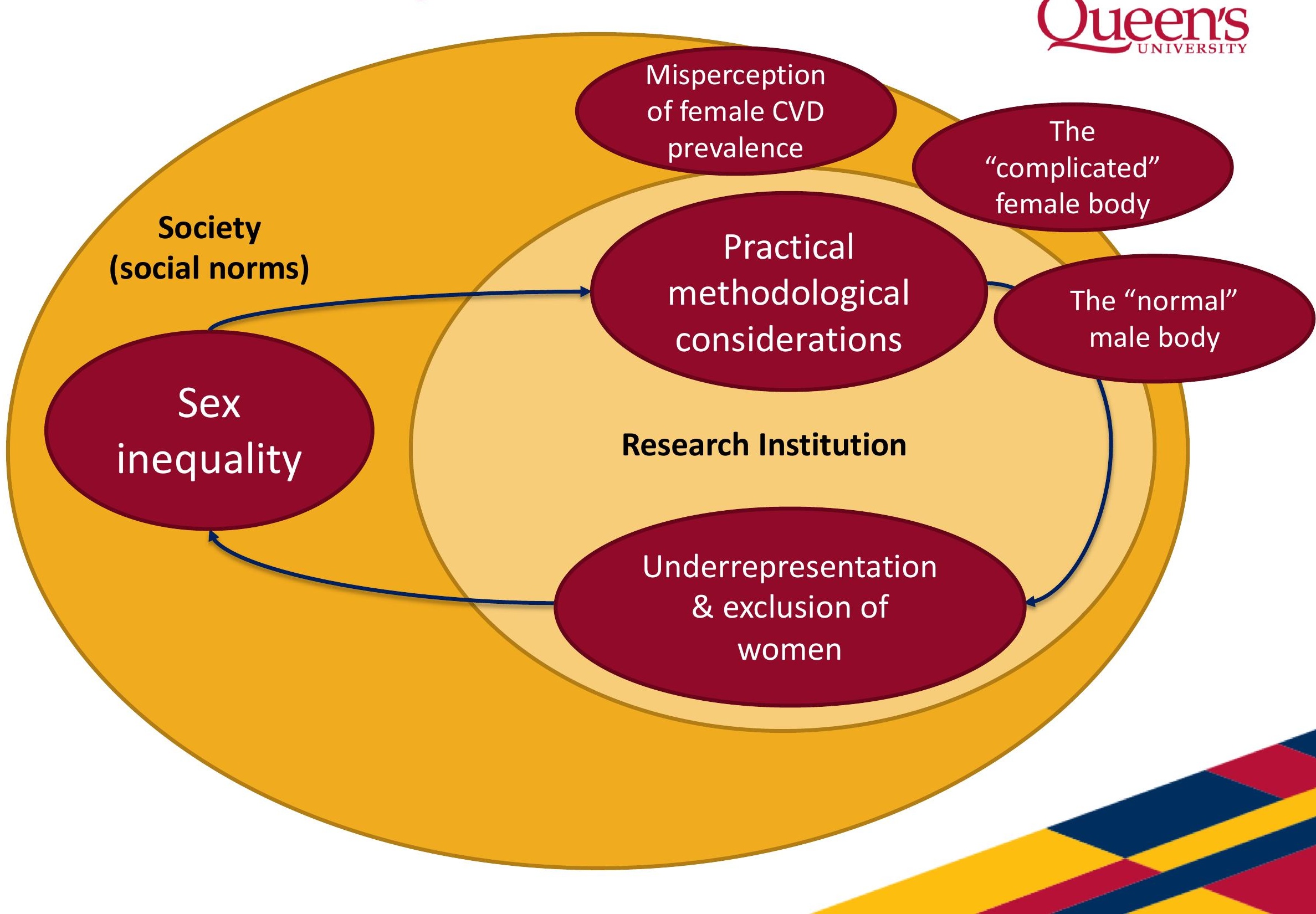




\section{Queen's}

\section{Systematic content analysis}

\section{General}

G1. Are the terms sex and/or gender defined in paper? (Yes, No)

G2. Are the terms sex and gender conflated or confused in paper?

(Yes, No - determined qualitatively)

G3. Is there evidence that the author knows the impact of sex/gender on the study outcome? (Yes, No - determined qualitatively)

G4. Is there evidence of a male norm? (Yes, No - determined qualitatively)

G5. If only one sex is included in the study, is this evident in the

title/abstract? (Yes, No, N/A)

\section{Interviews}

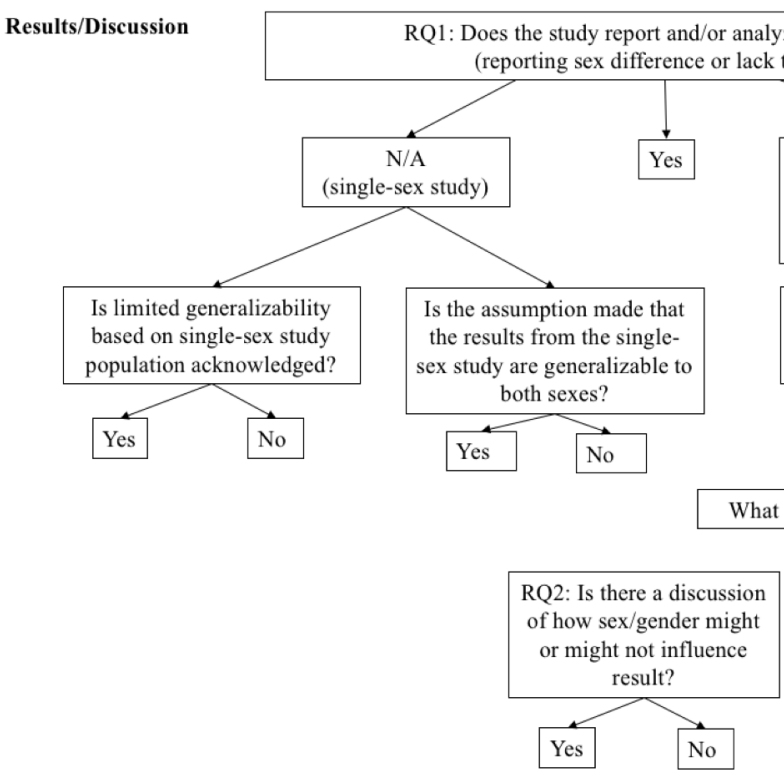

\section{Introduction}

IQ1: Is the study intended to test for sex differences? (Yes/No)

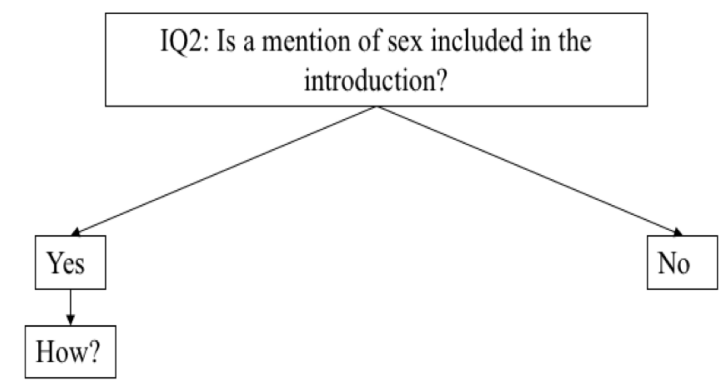

Methods
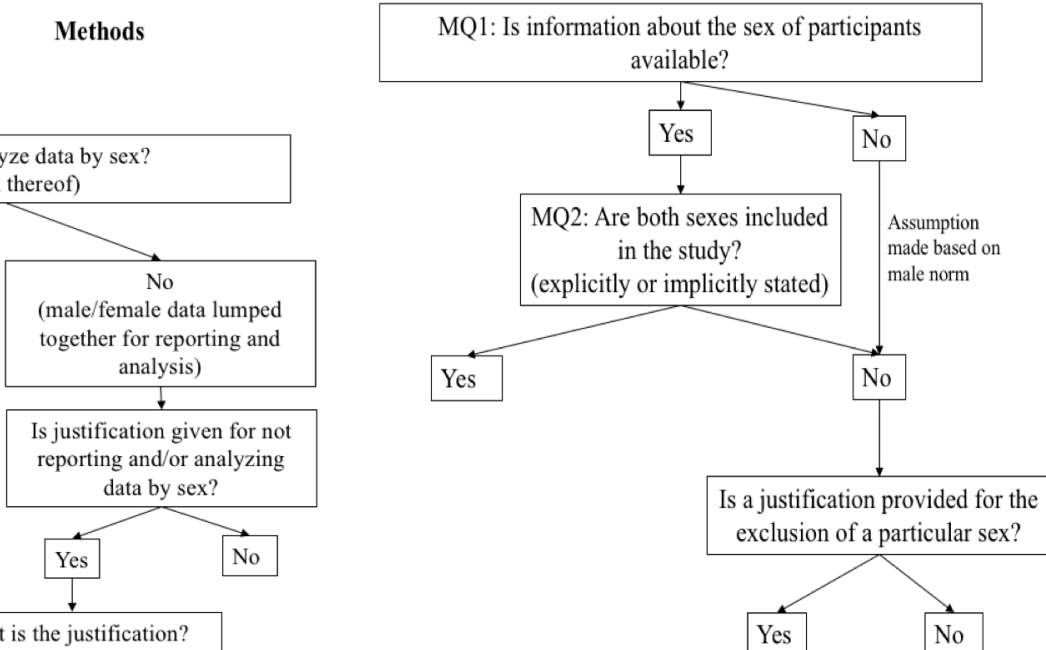
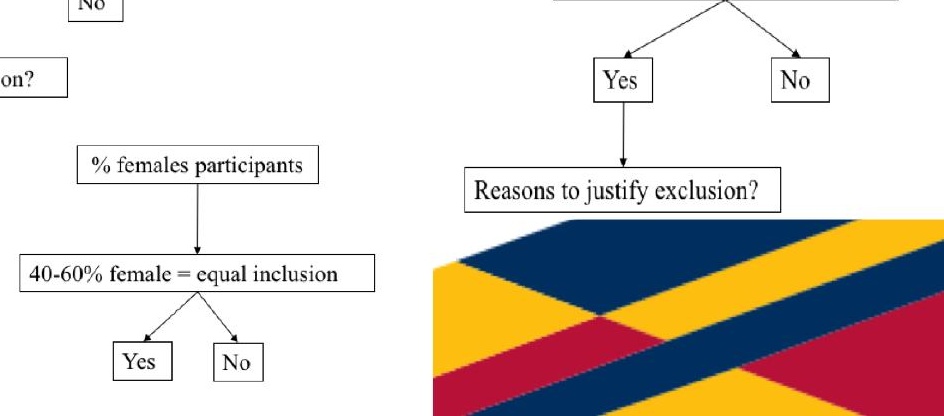
Part II - Statement of Significance

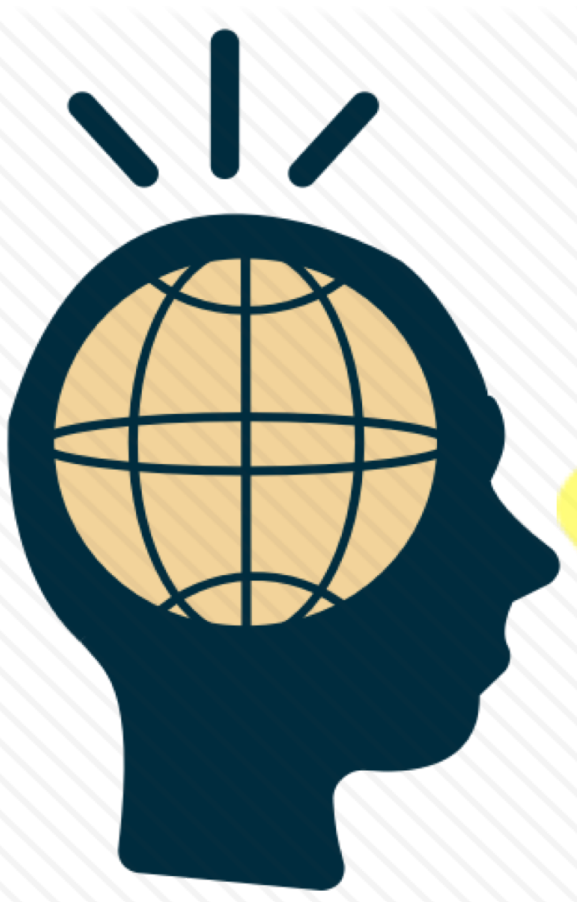

\title{
Construct
}

Maintain

\author{
Reinforce
}

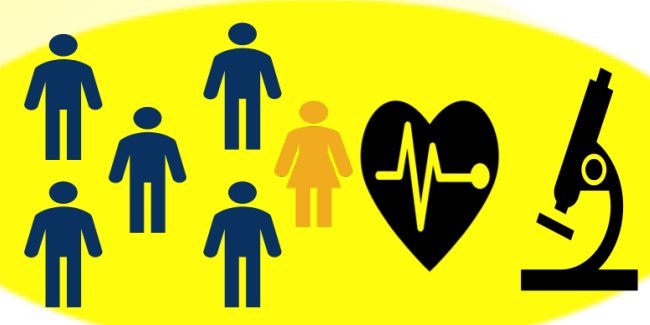


Take Home Message

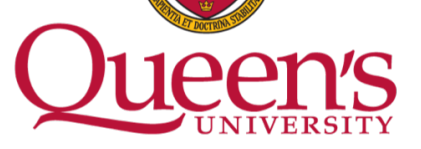

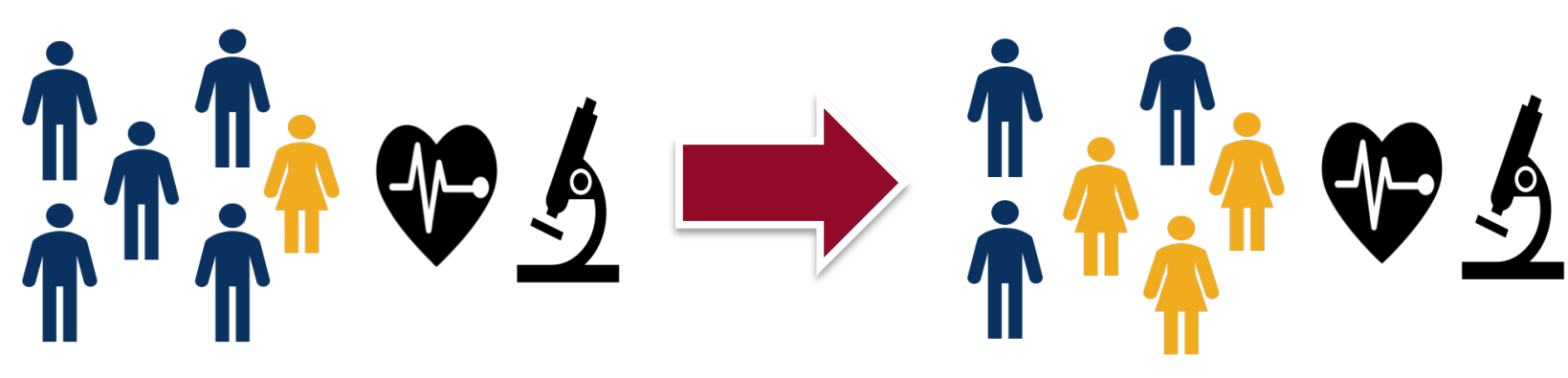

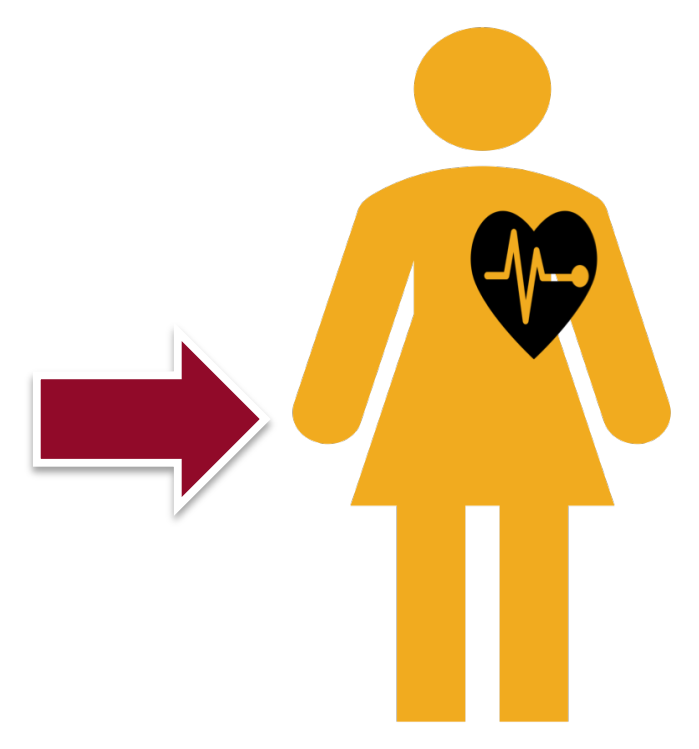




\section{Thank you!}

Ria Wilson, Kinesiology and Health Studies

14rcew@queensu.ca

Faculty Supervisors: Dr. Kyra Pyke, Dr. Mary Louise Adams 


\section{References}

Epstein, S. (2007). Inclusion: The politics of difference in medical research. Chicago: University of Chicago Press.

Government of Canada. (2016, December 21). Research Ethics: Tri-Council Policy Statement: Ethical Conduct for Research Involving Humans (TCPS). Retrieved 6 February 2019, from

http://science.gc.ca/eic/site/063.nsf/eng/h_76504BFE.html

Heart and Stroke Foundation of Canada. (2018). Ms.Understood: Heart \& Stroke 2018 Heart Report. Retrieved from https://www.heartandstroke.ca/-/media/pdf-files/canada/2018-heart-month/hs_2018-heartreport_en.ashx

Institute of Medicine (US) Committee on Ethical and Legal Issues Relating to the Inclusion of Women in Clinical Studies. (1994). Women and Health Research: Ethical and Legal Issues of Including Women in Clinical Studies: Volume I. (A. C. Mastroianni, R. Faden, \& D. Federman, Eds.). Washington (DC): National Academies Press (US). Retrieved from http://www.ncbi.nlm.nih.gov/books/NBK236536/

Kaufert, P. (1999). The vanishing woman: Gender and population health. In T. Pollard \& S. Brin Hyatt (Eds.), Sex, gender and health (pp. 118-36). Cambridge: Cambridge University Press.

Lippman, A. (2006). The inclusion of women in clinical trials: are we asking the right questions? Toronto, Canada: Women and Health Protection. 